\title{
Fluid Responsiveness in the Postoperative Period: a Prospective Study in Non-critically Ill Patients
}

Silvia Cicala MD, Sergio Cocimano MD, Elyana Wohl MD, Mattia Portinari MD, Sheldon Magder MD, Gabriele Baldini MD Department of Anesthesia, McGill University, Montreal General Hospital, Montreal, QC, Canada

\section{Background}

- The incidence of Fluid Responsiveness (FR) in noncritically ill surgical patients and the proportion of patients in whom Stroke Volume (SV) significantly increases after a bolus of intravenous fluids (Volume Expansion, VE) are unknown after surgery

- Although being Fluid Responder (FRer) does not necessarily imply being hypovolemic, it remains to be determined whether postoperative FR is associated with a higher rate of complications

\section{Objectives}

1. Determine the incidence of FR in non-critically ill surgical patients after major surgery

2. Establish if postoperative FR predicts and is associated with a higher rate of complications

3. Determine the proportion of patients in whom SV significantly increases after VE
Materials and Methods

- Adult patients undergoing major thoracic or abdominal surgery, not requiring intensive care unit admission, and treated with a surgery-specific Enhanced Recovery Program were enrolled (NCT02418663)

- FR was assessed soon after surgery, and daily for the first 72 h. SV was measured with the $\operatorname{ccNexfin}{ }^{\circledR}{ }^{1,2}$. FR was also assessed on call when VE was clinically deemed

- A patient was considered FRer if SV increased $\geq 15 \%$ within 5 minutes after a Fluid Challenge (FC) or after $\mathrm{VE}$, at least 1 time in the first 3 postoperative days

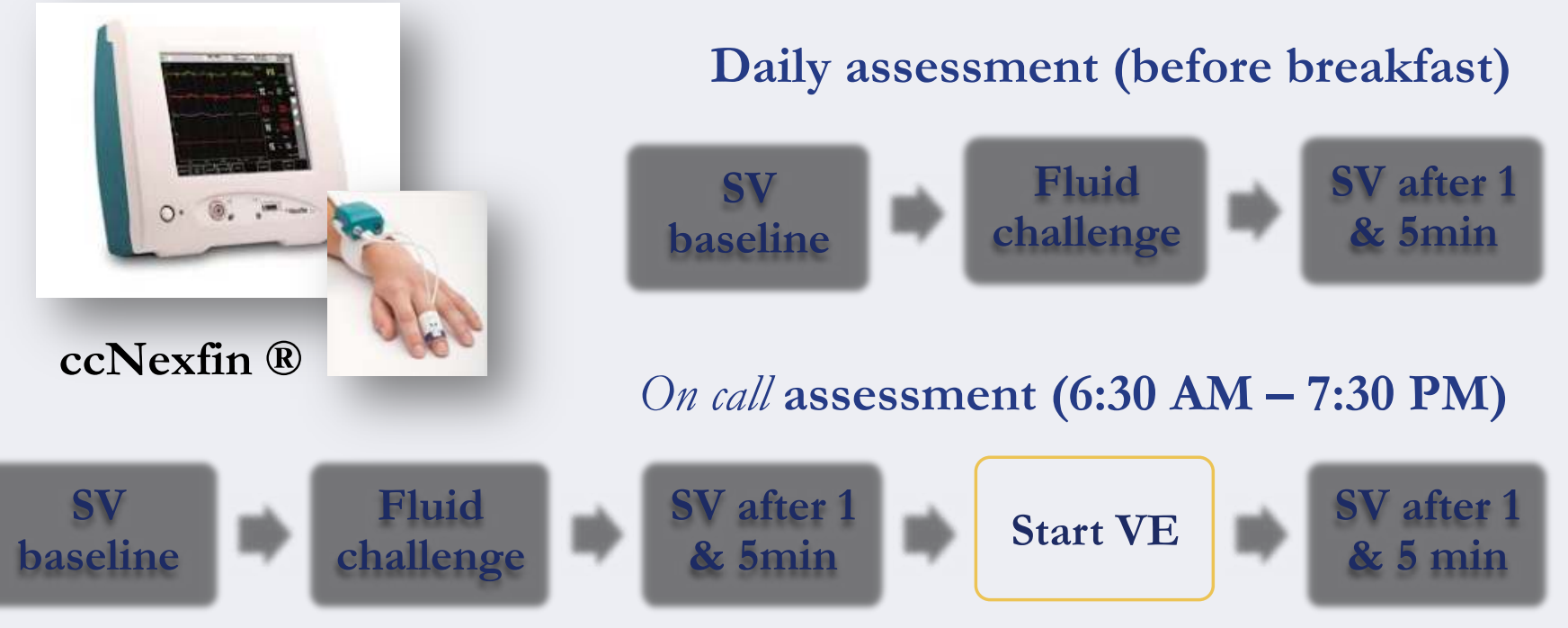

FC $=250 \mathrm{ml} \mathrm{Lactated} \mathrm{Ringer's} \mathrm{over} 5 \mathrm{~min}$

Results

- FR after a FC was present in 32 out of 88 patients $(36.4 \%)$

- VE was clinically required in 7 patients (7.9\%); only 1 (14.3\%) was FRer (Figure 1)

- FC predicted FR in $85 \%$ of patients (ROC curve area=0.91)
- FR was not associated and did not predict 30-day complications $\left(\mathrm{OR}_{\text {adjusted }}=0.61,95 \% \mathrm{CI}=0.22\right.$ to 1.72$)$ (Table 1)

\begin{tabular}{|c|c|c|c|c|}
\hline & $\begin{array}{c}\text { FRer } \\
(n=32)\end{array}$ & $\begin{array}{c}\text { Not FRer } \\
(n=56)\end{array}$ & $\begin{array}{c}\text { RR }_{\text {Adjusted* }} \\
\text { (95\%CI) }\end{array}$ & p-value \\
\hline Lenght of hospital stay, days & $4.5(3-7.75)$ & $4(3-6)$ & - & - \\
\hline 30-day complications $* * * n(\%)$ & $15(46.9)$ & $22(39.3)$ & $1.04(0.58$ to 1.90$)$ & 0.692 \\
\hline In-hospital & $15(46.9)$ & $17(30.4)$ & $1.35(0.70$ to 2.63$)$ & 0.909 \\
\hline Post-discharge & $2(6.3)$ & $6(10.7)$ & 0.68 (0.12 to 3.84$)$ & 0.739 \\
\hline Medical & $11(34.4)$ & $16(28.6)$ & 0.94 (0.43 to 2.04$)$ & 0.671 \\
\hline Surgical & $10(31.3)$ & $11(19.6)$ & 1.67 (0.75 to 3.75$)$ & 0.687 \\
\hline Intensive Care Unit admission, $n(\%)$ & $5(15.6)$ & $3(5.4)$ & $1.47(0.42$ to 5.14$)$ & - \\
\hline \multirow[t]{2}{*}{ 30-day Clavien, $n(\%) \quad$ I-II } & $7(21.9)$ & $17(30.4)$ & $0.44(0.18$ to 1.10$)$ & 1.000 \\
\hline & $8(25.0)$ & $5(8.9)$ & $5.3(0.74$ to 38.1$)$ & - \\
\hline 30-day CCI & $0(0-30.7)$ & $0(0-11.3)$ & - & - \\
\hline 30-day Emergency department visit, $n(\%)$ & $1(3.1)$ & $5(8.9)$ & - & 1.000 \\
\hline 30-day Readmission, $n(\%)$ & $3(9.4)$ & $6(10.7)$ & $1.17(0.25$ to 5.40$)$ & 0.710 \\
\hline
\end{tabular}

Table 1. *Adjusted for age, duration of surgery (>150 min), intraoperative fluid $(<1000 \mathrm{ml})$, estimated blood loss (>500 ml), negative fluid balance Day 1; **patients with at least 1 complication. CCI=Comprehensive Complication Index.

\section{Conclusions}

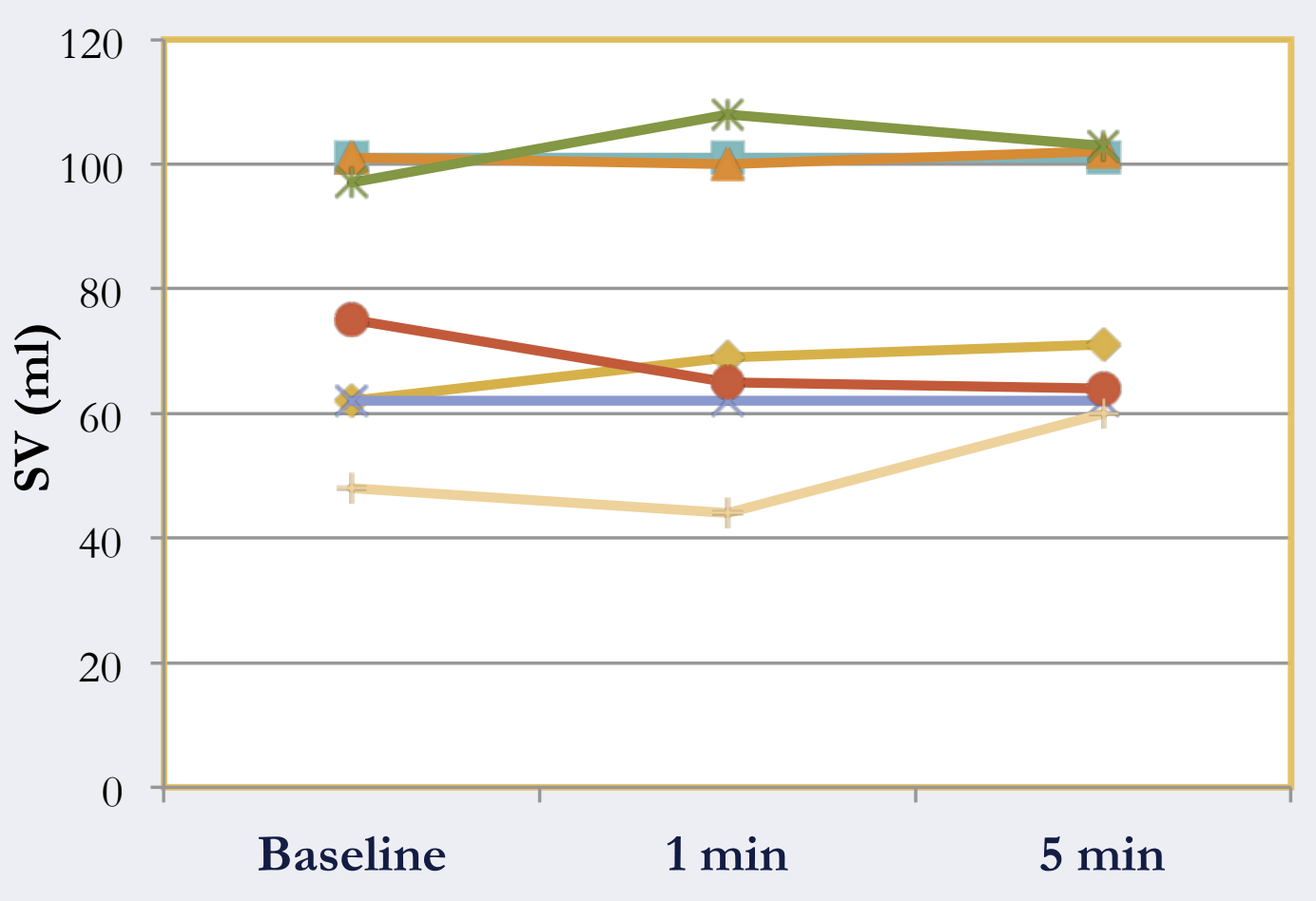

Figure 1. On call FR assessment: SV before and after VE.

- These preliminary results suggest that $36.4 \%$ of non-critically ill surgical patients are FRer after surgery

- After controlling for confounders, FR does not predict and is not associated with a higher rate of complications

- Fluid boluses administered based on clinical signs of hypovolemia rarely determine a significant increase of SV and might be potentially harmful

\section{References:}

1. Bogert LW, Wesseling KH, Schraa O, Van Lieshout EJ, de Mol BA, van Goudoever J, Westerhof BE, van Lieshout JJ. Pulse contour cardiac output derived from non-invasive arterial pressure in cardiovascular disease. Anaesthesia 2010; 65: 1119-25

2. Broch O, Renner J, Gruenewald M, Meybohm P, Schottler J, Caliebe A, Steinfath M, Malbrain M, Bein B. A comparison of the Nexfin ${ }^{\circledR}$ and transcardiopulmonary thermodilution to estimate cardiac output during coronary artery surgery. Anaesthesia $2012 ; 67: 377-83$ 